\title{
QUALIDADE MICROBIOLÓGICA DE LEITE CRU REFRIGERADO E ISOLAMENTO DE BACTÉRIAS PSICROTRÓFICAS PROTEOLÍTICAS ${ }^{1}$
}

\author{
Cláudia Lúcia de Oliveira PINTO ${ }^{2 *}$, Maurílio Lopes MARTINS ${ }^{3}$, Maria Cristina Dantas VANETTI ${ }^{3}$
}

\begin{abstract}
RESUMO
A estocagem do leite cru refrigerado na fonte de produção reduz perdas econômicas por atividade acidificante de bactérias mesofílicas, mas permite a seleção de bactérias psicrotróficas relacionadas a problemas tecnológicos e econômicos na indústria de laticínios. Com o objetivo de avaliar a qualidade microbiológica de leite cru, foram analisadas amostras provenientes de tanques de refrigeração individual, coletivos e do silo de uma indústria processadora de leite. Além disso, bactérias psicrotróficas proteolíticas foram isoladas do leite cru refrigerado e caracterizadas quanto à reação ao Gram e fermentação de glicose. O leite cru refrigerado mantido no silo industrial não atendeu ao padrão microbiológico legal e apresentou contagens microbianas significativamente superiores às do leite mantido em tanques individuais ou coletivos. Diferença significativa na contaminação por mesófilos e psicrotrófilos proteolíticos e não proteolíticos e por Pseudomonas foi observada entre as amostras coletadas nos tanques de refrigeração e no silo industrial. A microbiota Gram-negativa foi isolada com maior freqüência, especialmente bactérias Gram-negativas não fermentadoras de glicose. Palavras-chave: leite refrigerado, microbiota psicrotrófica, qualidade microbiológica.
\end{abstract}

\section{SUMMARY}

MICROBIAL QUALITY OF RAW REFRIGERATED MILK AND ISOLATION OF PSYCHROTROPHIC PROTEOLYTIC BACTERIA. Storing refrigerated raw milk in the source of production reduces economic losses which occur due to the acidifying activity of mesophilic bacteria. Nevertheless, this process selects psychrotrophic bacteria that cause technological and economic problems to the dairy industry. Samples of individual and collective refrigerated tanks and samples from an industrial silo in a dairy industry were collected and analyzed to evaluate the microbiological quality of raw milk. Furthermore, proteolytic psychrotrophic bacteria were isolated from refrigerated raw milk and characterized according to the Gram reaction and glucose fermentation. The refrigerated raw milk from the industrial silo was not compatible with legal microbiological standards, and its microbial count was significantly higher than milk from individual and collective tanks. A significant difference of contamination by mesophiles, proteolytic and non-proteolytic psychrotrophs, and Pseudomonas was observed in samples collected from refrigeration tanks compared to samples collected from the industrial silo. The Gram-negative microbiota was isolated more often, especially the glucose non-fermentative Gram-negative bacteria.

Keywords: raw milk, psychrotrophic microbiota, microbial quality.

\section{1 - INTRODUÇÃO}

A implementação da estocagem do leite cru refrigerado na fonte de produção iniciou-se no Brasil, na década de 90, sendo regulamentada pelo Ministério da Agricultura em 2002 [4]. Esta prática reduz os custos operacionais de produção, incluindo a deterioração do leite por atividade acidificante de bactérias mesofílicas. Porém, pode ocasionar problemas tecnológicos associados à atividade de enzimas proteolíticas e lipolíticas de bactérias psicrotróficas. Muitas destas enzimas são termorresistentes [23, 33] e estão relacionadas às perdas de qualidade e à redução da vida de prateleira do leite UHT e de outros produtos lácteos [8, 9, $11,17,18,22,24,28,35,39,40]$.

A microbiota psicrotrófica contaminante do leite inclui espécies de bactérias Gram-negativas dos gêneros Pseudomonas, Achromobacter, Aeromonas, Serratia, Alcaligenes,

\footnotetext{
${ }^{1}$ Recebido para publicação em 10/10/2005. Aceito para publicação em 6/7/2006 (001621)

${ }^{2}$ Empresa de Pesquisa Agropecuária de Minas Gerais (EPAMIG/CTZM), Vila Gianetti, $n^{\circ}$ 46, Campus da Universidade Federal de Viçosa, CEP 36570-000, Viçosa (MG),

E-mail: clucia@epamig.ufv.br

${ }^{3}$ Departamento de Microbiologia, Universidade Federal de Viçosa,

CEP 36570-000, Viçosa (MG),

E-mail:mvanetti@ufv.br

* A quem a correspondência deve ser enviada
}

Chromobacterium e Flavobacterium e bactérias Gram-positivas dos gêneros Bacillus, Clostridium, Corynebacterium, Streptococcus, Lactococcus, Leuconostoc, Lactobacillus e Microbacterium spp. [10, 11, 12, 16, 21, 29, 30, 34, 42].

Bactérias do gênero Pseudomonas têm sido isoladas com maior freqüência do leite e de produtos lácteos refrigerados [11, 13, 14, 15, 43], embora não representem mais do que $10 \%$ da microbiota do leite cru recém-ordenhado [35]. Esse gênero inclui espécies que apresentam um tempo de geração curto, entre $0{ }^{\circ} \mathrm{C}$ e $7{ }^{\circ} \mathrm{C}$, e uma temperatura mínima de crescimento baixa, de até $-10^{\circ} \mathrm{C}$ [35].

A contaminação dos produtos lácteos por bactérias psicrotróficas pode originar-se do suprimento de água de qualidade inadequada, deficiências de procedimentos de higiene e mastite [13, 14, 26, 32]. Portanto, procedimentos de higienização empregados na cadeia produtiva do leite constituem pontos críticos para a obtenção de uma matériaprima de alta qualidade.

No Brasil, não existe uma regulamentação específica quanto à qualidade microbiológica do leite cru destinado à fabricação de produtos lácteos específicos. Entretanto, com base nos dados da literatura, é imprudente a fabricação de produtos a partir do leite cru com contagem de psicrotróficos superior a 5,0 × $10^{6} \mathrm{UFC} / \mathrm{mL}$. Considerando a escassez de informações sobre a microbiota contaminante do leite após 
a implantação da Instrução Normativa ${ }^{\circ} 51$ do Ministério da Agricultura, Pecuária e Abastecimento, objetivou-se, neste trabalho, avaliar a qualidade microbiológica do leite cru refrigerado destinado à produção de leite UHT e isolar bactérias psicrotróficas proteolíticas predominantes.

\section{2 - MATERIAL E MÉTODOS}

\section{1 - Amostragem}

As amostras de leite cru refrigerado granelizado foram coletadas em uma indústria de laticínios localizada na Zona da Mata Mineira, receptora e processadora de, aproximadamente, 200.000 L de leite por dia. Nesta empresa havia uma rede de fornecedores de matéria-prima composta de 230 tanques individuais e 90 tanques coletivos, com capacidade entre 250 e $3.000 \mathrm{~L} /$ tanque, atendendo a, aproximadamente, 1.000 cooperados. Um percentual aproximado de $98 \%$ do leite é recebido pela empresa de forma granelizada. Foram coletadas 33 amostras de leite em tanques de refrigeração individuais e 12 amostras em tanques coletivos. Segundo a Norma ABNT NBR 5429 [1], a amostragem mínima deveria ser de 18 amostras para os 230 tanques individuais e nove amostras para os 90 tanques coletivos. Para a coleta, manuseio e manutenção das amostras, seguiram-se os procedimentos da Federação Internacional de Laticínios [25]. Amostras de $200 \mathrm{~mL}$ de leite cru refrigerado, estocado por, aproximadamente, $48 \mathrm{~h}$ em tanques de refrigeração individuais e coletivos, foram coletadas, aleatoriamente, em frascos de vidro esterilizados, em diferentes propriedades rurais. No momento da coleta de amostras, a temperatura de estocagem do leite foi medida e foram obtidas informações sobre a origem e o tratamento da água usada nos procedimentos de higienização. Após a coleta, as amostras foram imediatamente colocadas em banho de gelo, com temperatura inferior a $4{ }^{\circ} \mathrm{C}$ e transportadas ao laboratório para a realização das análises microbiológicas.

\section{2 - Caracterização da microbiota bacteriana contaminante do leite cru refrigerado}

\subsection{1 - Lactofermentação}

As amostras de leite cru refrigeradas foram submetidas à prova de lactofermentação, para verificação do tipo de microbiota mesofílica predominante no leite, com base no aspecto, odor e tipo de coágulo formado. Alíquotas de $10 \mathrm{~mL}$ do leite foram incubadas a $37^{\circ} \mathrm{C}$, por 24 a $48 \mathrm{~h}$ para posterior avaliação do tipo de coágulo formado [3].

\subsection{2 - Contagens de bactérias mesofílicas e mesofílicas proteolíticas}

Foi realizada em Ágar Caseinato para Métodos Padronizados - SMCA de acordo com metodologia recomendada por FRANK et al. [19].

\subsection{3 - Contagem de bactérias} psicrotróficas e isolamento e caracterização de bactérias psicrotróficas proteolíticas

Diluições decimais das amostras do leite cru foram plaqueadas em SMCA para contagem de bactérias psicrotróficas e psicrotróficas-proteolíticas viáveis, com incubação a $6,5^{\circ} \mathrm{C} \pm 0,5^{\circ} \mathrm{C}$, por 10 dias. A contagem de Pseudomonas spp. foi realizada após $72 \mathrm{~h}$ de incubação, a $22{ }^{\circ} \mathrm{C}$, em ágar base para Pseudomonas CM559 (Oxoid $^{\circledR}$ ), adicionado de cetrimida (10 mg/L), fucidina $(10 \mathrm{mg} / \mathrm{L})$ e cefalosporina (50 mg/L) (suplemento seletivo SR 103E, Oxoid ${ }^{\circledast}$ ). Os resultados foram expressos em Unidades Formadoras de Colônias - UFC/mL.

Foram selecionadas de três a quatro colônias de isolados com halos de clarificação e/ou de precipitação da caseína do meio de cultura SMCA, com as maiores diluições de amostras de leite cru. Os isolados foram purificados em ágar nutriente e conservados congelados a $-80{ }^{\circ} \mathrm{C}$, em caldo tripticaseína e soja - TSB, adicionado de $20 \%$ de glicerol. Quando necessário, a ativação dos isolados foi feita em caldo TSB, com incubação a $25^{\circ} \mathrm{C}$, por $48 \mathrm{~h}$.

Os isolados foram caracterizados quanto à morfologia e reação de Gram. O metabolismo fermentativo da glicose foi pesquisado nos isolados Gram-negativos em meio Rugai modificado por Pessoa e Silva (MBiolog Diagnósticos Ltda.). Os isolados que se apresentaram como Gram-negativos não-fermentadores de glicose foram avaliados quanto à produção de pigmentos fluorescentes, após o crescimento em SMCA, com o auxílio de uma lâmpada ultravioleta Spectroline, Modelo CA-160, com irradiação em comprimento de onda de $365 \mathrm{~nm}$.

\section{3 - Análises estatísticas}

Os dados referentes às contagens microbianas nas amostras dos diferentes grupos de microrganismos foram analisados comparando-se as médias entre tanques individuais, coletivos e no silo industrial, por meio da análise de variância e teste de Tukey a $5 \%$ de probabilidade. Além disso, foi realizada uma análise descritiva do percentual de amostras coletadas em tanques individuais, coletivos e no silo industrial quanto ao grau de contaminação pelos grupos de microrganismos avaliados, agrupando-as em diferentes faixas de contagens. Empregou-se, para as análises estatísticas, o Sistema de Análise Estatística - SAS [36].

\section{3 - RESULTADOS E DISCUSSÃO}

\section{1 - Caracterização da microbiota bacteriana do leite cru refrigerado}

\subsection{1 - Lactofermentação}

A maior variação nos tipos de coágulos formados na prova de lactofermentação foi observada nas amostras coletadas em tanques individuais de refrigeração de leite e a menor variação ocorreu nas amostras coletadas no silo 
industrial (Tabela 1). Um total de 64,7\% das amostras dos tanques individuais apresentou coágulos dos tipos: digerido, floculoso, caseoso ou sulcado, o que indica a predominância de microbiota proteolítica (Tabela 1). Coágulos homogêneos ou gelatinosos, observados em $32,3 \%$ das amostras coletadas em tanques individuais (Tabela 1), indicaram a predominância de bactérias láticas, que correspondem aos tipos de coágulos desejáveis à indústria de laticínios, por indicar a boa qualidade bacteriológica de amostras de leite cru. A ausência de coágulo, constatada em uma amostra coletada em tanque individual (Tabela 1), pode estar relacionada com a presença de resíduos de substâncias antimicrobianas. De acordo com BRAMLEY \& McKINNON [3], a ausência de coágulo na prova de lactofermentação é indicativa de presença de resíduos de substâncias antimicrobianas ou a presença de um número baixo de células microbianas. Nas amostras coletadas em tanques coletivos, 50\% apresentaram coágulo homogêneo ou gelatinoso e 50\% apresentaram coágulos dos tipos digerido, caseoso e floculoso, típicos de microbiota proteolítica (Tabela 1).

Em amostras de leite cru não-refrigeradas, FROEDER [20] também constatou uma incidência elevada de amostras com coágulo caseoso na prova de lactofermentação, indicando a predominância de microbiota proteolítica. Porém, esta autora observou a predominância de amostras com coágulos do tipo gelatinoso, típico de bactérias do ácido lático, o que pode ser relacionado com o fato de que as amostras de leite cru não eram refrigeradas.

TABELA 1 - Percentual dos tipos de coágulos formados na prova de lactofermentação, em amostras de leite refrigerado granelizado, coletadas em tanques de refrigeração individuais, coletivos e no silo industrial.

\begin{tabular}{lccc}
\hline \multicolumn{1}{c}{ Tipo de coágulo } & \multicolumn{3}{c}{ Origem } \\
\cline { 2 - 4 } & $\begin{array}{c}\text { Tanques } \\
\text { individuais }\end{array}$ & $\begin{array}{c}\text { Tanques } \\
\text { coletivos }\end{array}$ & Silo industrial \\
\hline Homogêneo & 29,4 & 37,5 & 50,0 \\
Gelatinoso & 2,9 & 12,5 & 0,0 \\
Floculoso & 17,6 & 25,0 & 0,0 \\
Caseoso & 2,9 & 0,0 & 0,0 \\
Digerido & 26,5 & 12,5 & 25,0 \\
Sulcado & 17,6 & 12,5 & 25,0 \\
Ausência de coágulo & 2,9 & 0,0 & 0,0 \\
\hline
\end{tabular}

\subsection{2 - Bactérias mesofílicas e mesofílicas proteolíticas}

Maior variação entre as contagens de bactérias mesofílicas foi observada nas amostras coletadas em tanques individuais e foi de $2,5 \times 10^{3} \mathrm{UFC} / \mathrm{mL}$ a $3,0 \times 10^{6} \mathrm{UFC} / \mathrm{mL}$. Estes resultados sugerem que, em algumas propriedades, as práticas higiênicas adotadas não garantiram uma contaminação baixa do leite armazenado sob refrigeração. A variação nas contagens de mesófilos nas amostras coletadas em tanques coletivos foi de $1,0 \times 10^{4} \mathrm{UFC} / \mathrm{mL}$ a $1,2 \mathrm{x}$ $10^{6} \mathrm{UFC} / \mathrm{mL}$, com média de $3,8 \times 10^{5} \mathrm{UFC} / \mathrm{mL}$.

Em quatro das 33 amostras coletadas em tanques individuais, constatou-se contagem padrão de mesófilos que não atenderam ao requisito microbiológico proposto pelo Ministério da Agricultura em vigor a partir de 01/07/2005, para as regiões Sul, Sudeste e Centro-Oeste, que é de 1,0 x $10^{6} \mathrm{UFC} / \mathrm{mL}$ [5]. O maior valor encontrado para a contagem de bactérias mesofílicas aeróbias nas amostras coletadas do silo industrial foi de 5,5 x $10^{6} \mathrm{UFC} / \mathrm{mL}$. Este número é semelhante aos valores constatados por SILVA [38] em amostras de leite cru coletadas em silos industriais de laticínios localizados no Estado de São Paulo e inferior aos valores constatados para as amostras provenientes dos Estados do Rio Grande do Sul (1,4 x 10 $\left.0^{7} \mathrm{UFC} / \mathrm{mL}\right)$ e Goiás (1,9 x $10^{7} \mathrm{UFC} / \mathrm{mL}$ ). De acordo com o autor, contagens mais baixas encontradas nas amostras coletadas no Estado de São Paulo podem ter sido influenciadas pela menor distância entre os centros de produção de leite e a fábrica de laticínios.

A contaminação do leite cru refrigerado por bactérias mesofílicas aeróbias variou entre $1,4 \times 10^{6} \mathrm{UFC} / \mathrm{mL}$ e 5,5 x $10^{6} \mathrm{UFC} / \mathrm{mL}$ e este número está acima do padrão estabelecido na legislação vigente [5]. A menor variação na população mesofílica nas amostras analisadas pode estar associada à constante homogeneização do leite no silo enquanto que, a maior contaminação dessas amostras pode ser resultante da mistura de leite cru de origens e graus de contaminação diferentes. Além disso, deve-se considerar que contaminações adicionais e crescimento microbiano podem ocorrer durante o transporte e a estocagem na indústria. Esse resultado é diferente do apresentado por SILVA [37], que encontrou uma grande variação entre os valores mínimo, mediano e máximo de mesófilos, respectivamente de $1,9 \times 10^{4} \mathrm{UFC} / \mathrm{mL} ; 3,2 \times$ $10^{6} \mathrm{UFC} / \mathrm{mL}$; e $1,6 \times 10^{8} \mathrm{UFC} / \mathrm{mL}$, em amostras de leite cru refrigerado, coletadas no silo de uma indústria e destinadas ao processamento de leite UHT.

A contaminação elevada constatada nas amostras de leite cru refrigerado pode estar associada com procedimentos de higienização inadequados no sistema de produção, considerando que resíduos de leite presentes nas superfícies dos equipamentos constituem nutrientes para o crescimento de bactérias que contaminam o produto em etapas subseqüentes do processamento. Além disso, o contato do leite com animais sujos, ambientes inadequados de produção, falhas na velocidade de resfriamento do leite para temperaturas inferiores a $4,4{ }^{\circ} \mathrm{C}$ e leite proveniente de animais com mastite também podem resultar em contagens microbianas elevadas.

Não houve diferença $(\mathrm{p}<0,05)$ entre as médias de contagens de bactérias mesofílicas proteolíticas das amostras dos tanques individuais e coletivos. Porém, a média de mesofílicos proteolíticos em amostras de silo industrial diferiu das encontradas nas amostras coletadas nos tanques individuais e coletivos (Tabela 2).

\subsection{3 - Bactérias psicrotróficas e psicrotróficas proteolíticas}

A contagem de bactérias psicrotróficas no leite cru refrigerado variou entre $2,0 \times 10^{2} \mathrm{UFC} / \mathrm{mL}$ e $1,0 \times 10^{7} \mathrm{UFC} / \mathrm{mL}$ nas amostras coletadas em tanques individuais, entre $8,9 \times$ 
TABELA 2 - Médias dos logaritmos dos números de unidades formadoras de colônias (UFC/mL) de bactérias mesófilas, mesófilas proteolíticas, psicrotróficas, psicrotróficas proteolíticas e de Pseudomonas spp., de amostras coletadas em tanques de refrigeração individuais, coletivos e no silo industrial.

\begin{tabular}{lccccc}
\hline Local de amostragem & Mesófilas & Mesófilas proteolíticas & Psicrotróficas & Psicrotróficas proteolíticas & Pseudomonas spp. \\
\hline Tanque Individual & $5,13^{\mathrm{a}}$ & $4,65^{\mathrm{a}}$ & $4,49^{\mathrm{a}}$ & $3,62^{\mathrm{a}}$ & $3,94^{\mathrm{a}}$ \\
Tanque Coletivo & $5,26^{\mathrm{a}}$ & $4,85^{\mathrm{a}, \mathrm{b}}$ & $4,70^{\mathrm{a}, \mathrm{b}}$ & $3,83^{\mathrm{a}, \mathrm{b}}$ & $4,47^{\mathrm{a}, \mathrm{b}}$ \\
Silo Industrial & $6,36^{\mathrm{b}}$ & $5,66^{\mathrm{b}}$ & $6,20^{\mathrm{b}}$ & $5,25^{\mathrm{b}}$ & $5,84^{\mathrm{b}}$ \\
\hline
\end{tabular}

Médias seguidas de uma mesma letra nas colunas não diferem entre si, a 5\% de probabilidade, pelo teste de Tukey.

$10^{2} \mathrm{UFC} / \mathrm{mL}$ e $3,2 \times 10^{6} \mathrm{UFC} / \mathrm{mL}$ nos tanques coletivos e entre $5,6 \times 10^{5} \mathrm{UFC} / \mathrm{mL}$ e $6,4 \times 10^{6} \mathrm{UFC} / \mathrm{mL}$ nas amostras coletadas no silo industrial. Contagens mais elevadas de bactérias psicrotróficas também foram registradas por SILVA [38] em amostras de leite cru coletadas em silos de indústrias processadoras de leite UHT dos Estados de São Paulo, Rio Grande do Sul e Goiás. Nessas amostras, as contagens de bactérias psicrotróficas variaram entre $1,4 \times 10^{6} \mathrm{UFC} / \mathrm{mL}$ e $8,8 \times 10^{7} \mathrm{UFC} / \mathrm{mL}$ e diferenças significativas foram detectadas em função do Estado e da estação.

Os percentuais de amostras de leite cru refrigerado, com contagens de bactérias psicrotróficas superiores a $10 \%$ da contagem de mesófilos aeróbios foram de 57,6\%, 66,7\% e $100 \%$ nas amostras coletadas em tanques de refrigeração individuais, coletivos e silo industrial, respectivamente. Estes resultados indicam que, mais da metade das amostras de leite estocadas em tanques individuais e coletivos e todas as amostras estocadas no silo industrial não atendem ao padrão estabelecido por BRASIL [6], que determina o controle da contaminação da microbiota psicrotrófica de tal forma que sua contagem não exceda a $10 \%$ do número total de mesófilos aeróbios. Portanto, pode-se concluir que as condições higiênicas de produção e de armazenamento, de transporte e de refrigeração, nas diferentes etapas da cadeia produtiva do leite, não estão adequadas para minimizar a contaminação microbiana e o crescimento de bactérias psicrotróficas. Relação entre $47 \%$ e $80 \%$, entre a contagem de bactérias psicrotróficas e mesófilas aeróbias em amostras de leite cru estocadas a $4{ }^{\circ} \mathrm{C}$, por $48 \mathrm{~h}$ foi observada por CELESTINO et al. [7].

A contagem de bactérias psicrotróficas proteolíticas variou entre $5,0 \times 10^{1} \mathrm{UFC} / \mathrm{mL}$ e $1,2 \times 10^{6} \mathrm{UFC} / \mathrm{mL}, 1,4 \times$ $10^{2} \mathrm{UFC} / \mathrm{mL}$ e $2,5 \times 10^{5} \mathrm{UFC} / \mathrm{mL}$ e $8,1 \times 10^{4} \mathrm{UFC} / \mathrm{mL}$ e $6,5 \times 10^{5} \mathrm{UFC} / \mathrm{mL}$, nas amostras coletadas em tanques individuais, coletivos e no silo industrial, respectivamente. O resultado das amostras coletadas no silo industrial foi semelhante aos apresentados por SILVA [37]. Observou-se que a contaminação por bactérias proteolíticas em amostras de leite de silos industriais, destinado ao processamento UHT, variou entre $2,3 \times 10^{3} \mathrm{UFC} / \mathrm{mL}$ e $8,0 \times 10^{5} \mathrm{UFC} / \mathrm{mL}$. Essa microbiota constituída por bactérias psicrotróficas proteolíticas, produtoras de proteases termorresistentes, constitui a maior causa de deterioração de amostras de leite cru refrigerado [35].

A contagem de Pseudomonas spp. variou entre $1,0 \times$ $10^{1} \mathrm{UFC} / \mathrm{mL}$ e $3,8 \times 10^{6} \mathrm{UFC} / \mathrm{mL}$, nas amostras coletadas em tanques individuais; entre $8,0 \times 10^{2} \mathrm{UFC} / \mathrm{mL}$ e $6,3 \times 10^{5}$ $\mathrm{UFC} / \mathrm{mL}$, nas dos tanques coletivos; e de $2 \times 10^{4} \mathrm{UFC} / \mathrm{mL}$ a $6,4 \times 10^{6} \mathrm{UFC} / \mathrm{mL}$, nas do silo industrial. As médias das contagens de Pseudomonas spp. foram $2,8 \times 10^{5} \mathrm{UFC} / \mathrm{mL}$, $1,3 \times 10^{5} \mathrm{UFC} / \mathrm{mL}$ e $2,0 \times 10^{6} \mathrm{UFC} / \mathrm{mL}$, nas amostras coletadas em tanques individuais, tanques coletivos e silo industrial, respectivamente.

Em 91,2\% das propriedades, onde as amostras de leite cru refrigeradas foram coletadas em tanques individuais, a água usada era proveniente de nascentes e, em 8,8\%, de poços. Naquelas propriedades onde os tanques eram coletivos, $75 \%$, 8,3\% e $16,7 \%$ da água empregada era proveniente de nascentes, poços e abastecimento municipal, respectivamente. As águas de nascentes e poços não eram submetidas a nenhum tipo de tratamento prévio de desinfecção para uso na ordenha e/ou na higienização de utensílios e equipamentos. A contaminação desses suprimentos de água não tratada pode contribuir para o aumento da contaminação do leite por bactérias deterioradoras, incluindo as do gênero Pseudomonas.

As amostras de leite coletadas no silo industrial apresentaram contagens de microrganismos sempre superiores $(\mathrm{p}<0,05)$ às encontradas em amostras dos tanques individuais e coletivos (Tabela 2). Durante a estocagem de amostras de leite cru sob refrigeração, CELESTINO et al. [7] observaram o aumento do número de bactérias psicrotróficas com atividades proteolíticas e lipolíticas. Os efeitos da estocagem sob refrigeração incluíram a ocorrência de proteólise e lipólise.

Diferenças significativas, em função do Estado e da estação, nas contagens de bactérias psicrotróficas, em amostras de leite cru refrigeradas coletadas em silos industriais, foram registradas por SILVA [38]. Contagens entre $1,4 \times 10^{6} \mathrm{UFC} / \mathrm{mL}$ e $8,8 \times 10^{7} \mathrm{UFC} / \mathrm{mL}$ foram constatadas pelo autor e os maiores valores foram nas amostras coletadas na estação chuvosa. Uma correlação positiva entre a contagem de bactérias psicrotróficas do leite cru e o aumento da viscosidade do leite UHT também foi observada, sugerindo a atividade de enzimas proteolíticas termorresistentes. As contagens de bactérias psicrotróficas encontradas por SILVA [38] nas amostras de leite cru refrigerado, coletadas no silo industrial nos diferentes Estados, foram superiores às constatadas neste estudo. Estes resultados podem ser relacionados com as diferenças das condições de cada indústria, incluindo o tempo de refrigeração resultante do somatório de horas de refrigeração na fonte de produção, transporte até o posto e refrigeração, descarregamento-estocagem-carregamento no posto de refrigeração, transporte até a indústria e descarga e estocagem na planta industrial. 
A estocagem de amostras de leite tipo A, a $4{ }^{\circ} \mathrm{C}$ e a $8{ }^{\circ} \mathrm{C}$, resultou no aparecimento de sabor amargo no produto em decorrência da atividade proteolítica e de bactérias psicrotróficas, segundo THIELMAN [41], que ainda observou que o problema variou em função das condições higiênicas da granja leiteira. Esses dados reforçam a importância de investimentos e de medidas que aprimorem as técnicas de boas práticas de higiene na cadeia produtiva do leite.

Constatou-se, nas amostras coletadas em tanques coletivos, um maior percentual de amostras de leite cru refrigerado e granelizado contaminado com mesófilos, mesófilosproteolíticos, psicrotróficos, psicrotróficos proteolíticos e Pseudomonas, com contagens na faixa entre $10^{5} \mathrm{UFC} / \mathrm{mL}$ e $10^{6} \mathrm{UFC} / \mathrm{mL}$ (Tabela 3). Observou-se também que, na maioria das vezes, as amostras com contagens acima de $10^{6} \mathrm{UFC} / \mathrm{mL}$ foram coletadas no silo industrial (Tabela 3). Este resultado sugere que os procedimentos de higienização, associados ao tempo e à temperatura de estocagem da matéria-prima na fonte produtora e às condições de transporte, não foram suficientes para reduzir a contaminação e o crescimento dos microrganismos contaminantes.

Existe uma grande controvérsia entre a relação do número de bactérias contaminantes e os possíveis defeitos na qualidade do leite e derivados após o processamento. ADAMS et al. [2] observaram que populações altas de psicrotróficos não são necessárias para a produção de concentrações significativas de proteases termorresistentes. KOCAK \& ZADOW [27], ao estudarem o efeito da população bacteriana sobre a geleificação em leite UHT integral, estocado a $25{ }^{\circ} \mathrm{C}$, e a extensão da proteólise, também constataram que amostras de leite UHT processadas com contagem bacteriana alta e baixa geleificaram na mesma proporção. Os autores concluíram que o tempo de geleificação não pareceu estar associado somente com a qualidade microbiológica do leite.

Temperatura de refrigeração abaixo de $4{ }^{\circ} \mathrm{C}$ foi registrada principalmente em tanques individuais $(39,4 \%)$, que é a condição recomendada pela legislação. Em 58,3\% das amostras coletadas em tanques coletivos, foram observadas temperaturas entre $4{ }^{\circ} \mathrm{C}$ e $7{ }^{\circ} \mathrm{C}$ e, em $16,7 \%$ das amostras, a temperatura foi superior a $10^{\circ} \mathrm{C}$.

\subsection{4 - Isolamento e caracterização de bactérias psicrotróficas proteolíticas}

Foram isoladas 153 bactérias psicrotróficas proteolíticas de amostras de leite cru refrigeradas em tanques de granelização individuais, coletivos e no silo industrial. Dentre os isolados Gram-negativos (75,2\%), 27\% e $48 \%$ foram, respectivamente, Gram-negativos fermentadores e Gram-negativos não-fermentadores. A predominância do isolamento de bactérias Gram-negativas, observada nas amostras de leite cru refrigerado está de acordo com resultados de outras pesquisas, nas quais elas são consideradas como contaminantes mais freqüentes [11, 15]. Com base na fermentação da glicose em meio Rugai modificado, os isolados foram classificados em dois grupos: fermentadores e não fermentadores.

Bactérias não fermentadoras de glicose representaram o maior percentual dentre as isoladas. Neste grupo, estão incluídos gêneros como Acinetobacter, Aeromonas, Burkholderia, Chryseobacteriun (Flavobacterium), Chryseomonas, Moraxella e Pseudomonas, entre outros. Diversas pesquisas reportaram Pseudomonas fluorescens como a bactéria mais freqüentemente isolada de leite cru refrigerado. ADAMS et al. [2] constataram que de $70 \%$ a $90 \%$ dos psicrotróficos isolados de leite cru estocado a $4{ }^{\circ} \mathrm{C}$, por uma semana, eram Pseudomonas. ENEROTH et al. [13] observaram maior freqüência de isolamento de espécies de Pseudomonas ( $72 \%$ a $77 \%$ ) em amostras de leite cru, de leite pasteurizado e de amostras ambientais de indústrias de laticínios. A importância do controle da contaminação dessa bactéria na cadeia produtiva do leite é relacionada ao seu potencial enzimático, o qual pode variar em função da estirpe. Dentre os 66 isolados de Pseudomonas de leite cru e processado,

TABELA 3 - Percentual de amostras de leite cru coletadas nos tanques de refrigeração individuais, coletivos e no silo industrial, agrupadas em faixas de contagens de grupos de microrganismos.

\begin{tabular}{|c|c|c|c|c|c|c|c|}
\hline \multirow{2}{*}{$\begin{array}{c}\text { Grupo de } \\
\text { Microrganismo }\end{array}$} & \multirow[t]{2}{*}{ Tanque } & \multicolumn{6}{|c|}{ Faixa ( UFC/mL) } \\
\hline & & $10^{1}-10^{2}$ & $10^{2}-10^{3}$ & $>10^{3}-10^{4}$ & $>10^{4}-10^{5}$ & $>10^{5}-10^{6}$ & $>10^{6}$ \\
\hline \multirow[t]{3}{*}{ Mesófilos } & Individual & $-^{*}$ & - & 6,1 & 39,4 & 42,4 & 12,1 \\
\hline & Coletivo & - & - & 0,0 & 25,0 & 58,3 & 16,7 \\
\hline & Silo & - & - & 0,0 & 0,0 & 0,0 & 100,0 \\
\hline \multirow{3}{*}{$\begin{array}{l}\text { Mesófilos prote- } \\
\text { olíticos }\end{array}$} & Individual & - & - & 18,5 & 48,1 & 33,3 & 0,0 \\
\hline & Coletivo & - & - & 18,2 & 27,3 & 54,5 & 0,0 \\
\hline & Silo & - & - & 0,0 & 0,0 & 75,0 & 25,0 \\
\hline \multirow[t]{3}{*}{ Psicrotróficos } & Individual & - & 15,2 & 21,2 & 33,3 & 18,2 & 12,1 \\
\hline & Coletivo & - & 0,0 & 0,0 & 25,0 & 58,3 & 16,7 \\
\hline & Silo & - & 0,0 & 0,0 & 0,0 & 50,0 & 50,0 \\
\hline \multirow{3}{*}{$\begin{array}{l}\text { Psicrotróficos } \\
\text { proteolíticos }\end{array}$} & Individual & 8,0 & 24,0 & 36,0 & 24,0 & 4,0 & 4,0 \\
\hline & Coletivo & 0,0 & 30,0 & 20,0 & 30,0 & 20,0 & 0,0 \\
\hline & Silo & 0,0 & 0,0 & 0,0 & 50,0 & 50,0 & 0,0 \\
\hline \multirow{3}{*}{$\begin{array}{l}\text { Pseudomonas } \\
\text { spp. }\end{array}$} & Individual & 9,1 & 15,2 & 33,3 & 15,2 & 18,2 & 9,1 \\
\hline & Coletivo & 0,0 & 16,7 & 8,3 & 41,7 & 33,3 & 0,0 \\
\hline & Silo & 0,0 & 0,0 & 0,0 & 25,0 & 25,0 & 50,0 \\
\hline
\end{tabular}

*diluição não avaliada. 
$58 \%, 58 \%$ e $47 \%$ possuíam atividade de proteases, lipases e de lecitinase, respectivamente [43].

A produção de pigmentos fluorescentes foi constatada em $77,4 \%$ dos isolados não fermentadores de glicose. De acordo com os resultados descritos por MUIR [31], a microbiota psicrotrófica predominante do leite estocado em tanques de resfriamento na fonte de produção e em silos industriais é Gram-negativa e representa 90\% da microbiota total. Espécies do gênero Pseudomonas são os organismos mais comuns, com um percentual aproximado de $50 \%$ do tipo fluorescente. A principal espécie, $P$. fluorescens, é caracterizada pela produção de um pigmento fluorescente difusível durante o seu crescimento em meio apropriado.

\section{4 - CONCLUSÕES}

O leite cru refrigerado mantido no silo industrial não atendeu ao padrão microbiológico legal e apresentou contagens microbianas significativamente superiores às do leite mantido em tanques individuias ou coletivos. Bactérias Gram-negativas foram isoladas com maior freqüência dentre os psicrotróficos proteolíticos. A refrigeração do leite cru, por períodos prolongados, na fonte de produção ou na indústria, pode comprometer a sua qualidade, considerando a possibilidade de seleção de bactérias psicrotróficas proteolíticas. Portanto, há necessidade de investimentos contínuos em boas práticas para prevenção da contaminação e do crescimento microbiano na cadeia produtiva do leite para reduzir problemas tecnológicos e econômicos na indústria de laticínios.

\section{5 - REFERÊNCIAS BIBLIOGRÁFICAS}

[1] ASSOCIAÇÃO BRASILEIRA DE NORMAS TÉCNICAS - ABNT. Coletânea de Normas e Planos de Amostragem, v. 2, p. 1-50, 1985.

[2] ADAMS, D. M.; BARACH, J. T.; SPECK, M. L. Heat resistant proteases produced in milk by psychrotrophic bacteria of dairy origin. Journal of Dairy Science, v. 58, p. $828-835,1975$.

[3] BRAMLEY, A. J.; McKINNON, C. H. The microbiology of raw milk. 2.ed. In: ROBINSON, R. K. (Ed.). The microbiology of milk. London, UK: Elsevier Science Publishers, 1990. p. 163-208.

[4] BRASIL. Ministério da Agricultura, Pecuária e Abastecimento. Departamento de Inspeção de Produtos de Origem Animal. Instrução Normativa no 51, de 18 de setembro de 2002. Coleta de leite cru refrigerado e seu transporte a granel. Diário Oficial da República Federativa do Brasil, n. 172, p. 8-13, 20 set. 2002a. Seção I.

[5] BRASIL. Ministério da Agricultura, Pecuária e Abastecimento. Departamento de Inspeção de Produtos de Origem Animal. Instrução Normativa no 51, de 18 de setembro de 2002. Aprova e Oficializa o Regulamento técnico de identidade e qualidade de leite cru refrigerado. Diário Oficial da República Federativa do Brasil, n. 172, p. 13-22, 20 set. 2002b. Seção I.

[6] BRASIL. Ministério da Agricultura, Pecuária e Abastecimento. Regulamento da Inspeção Industrial e
Sanitária de Produtos de Origem Animal - RIISPOA. Brasília: 1980. 116 p.

[7] CELESTINO, E. L.; IYER, M.; ROGINSKI, H. The effects of refrigerated storage on the quality of raw milk. The Australian Journal of Dairy Technology, v. 51, p. 59-63, 1996.

[8] CHAMPAGNE, C. P.; LAING, R. R.; ROY, D.; MAFU,A. A.; GRIFFITHS, M. W. Psychrotrophs in dairy products: their effects and their control. Critical Reviews in Food Science and Nutrition, v. 34, p. 1-30, 1994.

[9] CHEN, L.; DANIEL, R. M.; COOLBEAR, T. Detection and impact of protease and lipase activities in milk and milk powders. International Dairy Journal, v. 13, p. 255-275, 2003.

[10] COLLINS, E. B. Heat resistant psychrotrophic microrganisms. Journal Dairy Research, v. 64, p. 157-160, 1981.

[11] COUSIN, M. A. Presence and activity of psychrotrophic microrganisms in milk and dairy products: a review. Journal of Food Protection, v. 45, p. 172-207, 1982.

[12] COUSIN, M. A.; MARTH, E. H. Lactic acid production by Streptococcus lactis and Streptococcus cremoris in milk precultured with psychrotrophic bacteria. Journal of Food Protection, v. 40, p. 406-410, 1977.

[13] ENEROTH, A.; AHRNÉ, S.; MOLIN, G. Contamination of milk with Gram-negative spoilage bacteria during filling of retail containers. International Journal of Food Microbiology, v. 57, p. 99-106, 2000a.

[14] ENEROTH, A.; AHRNÉ, S.; MOLIN, G. Contamination routes of Gram-negative spoilage bacteria in the production of pasteurized milk, evaluated by randomly amplified polymorphic DNA (RAPD). International Dairy Journal, v. 10, p. 325-331, 2000b.

[15] ENEROTH, A.; CHRISTIANSSON, A.; BRENDEHAUG, J.; MOLIN, G. Critical contamination sites in the production line of pasteurised milk, with reference to the psychrotrophic spoilage flora. International Dairy Journal, v. 8, p. 829-834, 1998.

[16] EWINGS, K. N.; O’CONNOR, R. E.; MITCHELL, G. E. Proteolytic microflora of refrigerated raw milk in south east Queensland. The Australian Journal of Dairy Technology, p. 65-68, 1984.

[17] FAJARDO-LIRA, C. E.; NIELSEN, S. S. Effect of psychrotrophic microorganisms on the plasmin system in milk. Jounal of Dairy Science, v. 81, p. 901-908, 1998.

[18] FOX, P. F. Heat-induced changes in milk proceding coagulation. Journal Dairy Science, v. 64, p. 2127-2137, 1981.

[19] FRANK, J. F.; CHRISTEN, G. L.; BULLERMAN, L. B. Tests for groups of microrganisms. 16.ed. In: MARSHALL, R. T. (Ed.) Standard methods for the examination of dairy products. New York: APHA, 1992. p. 271-286.

[20] FROEDER, E. Qualidade microbiológica e físico química do leite cru da bacia leiteira de Viçosa-MG. 1985. 54 f. Dissertação (Mestrado em Ciência e Tecnologia de Alimentos) -Universidade Federal de Viçosa, Viçosa, 1985.

[21] GARCÍA-ARMESTO, M. R.; SUTHERLAND, A. D. Temperature characterization of psychrotrophic and me- 
sophilic Bacillus species from milk. Journal of Dairy Research, v. 64, p. 261-270, 1997.

[22] GRIFFITHS, M. W.; PHILIPS, J. D.; MUIR, D. D. Effect of low-temperature storage on the bacteriology quality of raw milk. Food Microbiology, v. 4, p. 285-291, 1987.

[23] GRIFFITHS, M. W.; PHILIPS, J. D.; MUIR, D. D. Thermostability of proteases and lipases from a number of species of psychotrophic bacteria of dairy origin. Journal Applied Bacteriology, v. 50, p. 289-303, 1981.

[24] GRIFFITHS, M. W.; PHILLIPS, J. D.; WEST, I. G.; MUIR, D. D. The effect extend low - temperature storage of raw milk on the quality of pasteurized and UHT milk. Food Microbiology, v. 5, p. 75-87, 1988.

[25] INTERNATIONAL DAIRY FEDERATION - IDF. Milk and milk products - Methods of sampling. Brussels, 1985. 19 p. (International Standard, 50B)

[26] JAY, J. M. Modern Food Microbiology. 5.ed. New York: Chapman \& Hall, 1996. 661 p.

[27] KOCAK, H. R.; ZADOW, J. G. Age gelation of UHT whole milk as influenced by storage temperature. The Australian Journal of Dairy Technology, n. 1, p.14-21, 1985.

[28] LAW, B. A.; ANDREWS, A. T.; SHARPE, A. E. Gelation of ultra-high-temperature-sterilized milk by proteases from a strain of Pseudomonas fluorescens isolated from raw milk. Journal of Dairy Research, v. 44, p.145-148, 1977.

[29] MATTA, H.; PUNJ, V. Isolation and identification of proteolytic psychrotrophic sporeforming bacteria from milk. Indian Journal of Dairy Science, v. 49, p.695-699, 1996.

[30] MATTA, H.; PUNJ, V. Isolation and identification of lipolytic, psychrotrophic, spore forming bacteria from raw milk. Internation Journal of Dairy Technology, v. 52, p. 59-62, 1999.

[31] MUIR, D. D. The shelf-life of dairy products: 3. Factors influencing intermediate and long life dairy products. Journal of the Society of Dairy Technology, v. 49, p. 67-72, 1996.

[32] MURPHY, S. C.; BOOR, K. J. Trouble-shooting sources and causes of high bacteria counts in raw milk. Dairy, Food and Environmental Sanitation, v. 20, p. 606-611, 2000.

[33] PATEL, T. R.; BARTLETT, F. M.; HAMID, J. Extracellular heat-resistant proteases of psychrotrophic pseudomonads. Journal of Food Protection, v. 46, p. 90-94, 1983.
[34] RYSER, E. Microorganisms of importance in raw milk. Michigan Dairy Review, v. 8, p. 7-9, 1999.

[35] SØRHAUG, T.; STEPANIAK, L. Psychrotrophs and their enzymes in milk and dairy products: Quality aspects. Trends in Food Science \& Technology, v. 8, p. 35-37, 1997.

[36] S. A. S. INSTITUTE. USER'S GUIDE: STATISTICS. VERSION 6.1.2. CARY, U.S.A. North Carolina State University, 1996. CD-ROM.

[37] SILVA, E. O. T. R. Leite longa vida: avaliação de alguns parâmetros de qualidade dos leites cru e processado. 2001. 130 f. Tese (Doutorado em Epidemiologia Experimental e Aplicada à Zonoses) - Universidade de São Paulo, São Paulo, 2001.

[38] SILVA, P. H. F. Leite UHT: Fatores determinantes para sedimentação e gelificação. 2003. 147p. Tese (Doutorado em Ciência dos Alimentos) - Universidade Federal de Lavras, Lavras, 2003.

[39] SPECK, M. L.; ADAMS, D. M. Heat resistent proteolytic enzymes from bacterial sources. In: Symposium: impact of heat stable microbial enzymes in food processing. Journal of Dairy Science, v. 59, p. 786-789, 1976.

[40] TERADA, A.; TANAKA, S.; UCHIDA, K. Studies on psychrotrophic bacteria of bovine milk, proteolytic and lipolytic activies of psychrotrophic bacteria isolated from raw milk. Bulletin of the Nippon Veterinary and Zootechnical College, v. 31, p. 222-228, 1982.

[41] THIELMANN, C. Avaliação das características da qualidade e prazo de validade de leite tipo "A". 1994. 127 f. Dissertação (Mestrado em Ciência e Tecnologia de Alimentos) - Universidade Federal de Viçosa, Viçosa, 1994.

[42] WALKER, S. J. Major spoilage micro-organisms in milk and dairy products. Journal of the Society of Dairy Technology, v. 41, p. 91-92, 1988.

[43] WIEDMANN, M.; WEILMEIER, D.; DINEEN, S. S; RALYEA, R.; BOOR, J. K. Molecular and phenotypic characterization of Pseudomonas spp. isolated from milk. Applied and Environmental Microbiology, v. 66, p. 2085-2095, 2000.

\section{6 - AGRADECIMENTOS}

Os autores agradecem à Fundação de Amparo à Pesquisa do Estado de Minas Gerais - FAPEMIG - pelo apoio financeiro e ao Prof. José Benício Paes Chaves (DTA/UFV), pelas críticas e sugestões. 